\title{
Effects of marine reserves on California spiny lobster are robust and modified by fine-scale habitat features and distance from reserve borders
}

\author{
Matthew C. Kay ${ }^{1, *}$, Hunter S. Lenihan ${ }^{1}$, Matthew J. Kotchen ${ }^{2}$, Christopher J. Miller ${ }^{3}$ \\ ${ }^{1}$ Bren School of Environmental Science and Management, University of California, Santa Barbara, California 93106-5131, USA \\ ${ }^{2}$ School of Forestry \& Environmental Studies, Yale University, New Haven, Connecticut 06511, USA \\ ${ }^{3}$ California Lobster and Trap Fishermen's Association, PO Box 2294, Capo Beach, California 92624, USA
}

\begin{abstract}
Studies of marine reserves often describe mean differences in organism size or abundance inside versus outside reserves, but recent work indicates that these differences are influenced by habitat and proximity of sites to reserve borders. In this study, we measured mean effects of reserves and the influence of distance from reserve borders on the number and size of legal ( $\geq 82.5 \mathrm{~mm}$ carapace length [CL]) California spiny lobster Panulirus interruptus trapped at sites across a reserve network at the Santa Barbara Channel Islands, California, USA. Additionally, we controlled for habitat variability across sites (1) by measuring relative abundance of sublegal adult lobsters (i.e. those not removed through fishing) and (2) through visual SCUBA surveys on which we quantified fine-scale habitat features. Traps placed in reserves yielded more $\left(4.81 \mathrm{trap}^{-1}\right)$ and larger $(7.03 \mathrm{~mm} \mathrm{CL}$ ) legal-sized lobsters than traps placed outside. Multiple linear regression revealed that 2.43 more legal lobsters per trap were captured for every $1 \mathrm{~km}$ moved from borders towards reserve centers. Additionally, lobsters tagged and released immediately inside reserve borders were recaptured in areas open to fishing at a higher rate than lobsters tagged and released farther inside reserves. These results suggest that abundance gradients inside reserve borders were caused by net emigration of lobsters (spillover). Sublegal lobsters were more abundant inside reserves and nearer to reserve centers, but these increases were much smaller in magnitude than for legal-sized lobsters. Our results indicate that the differences we observed for legalsized lobsters were driven primarily by reserve effects but were partially influenced by habitat heterogeneity.
\end{abstract}

KEY WORDS: Reef $\cdot$ Structure $\cdot$ Spillover $\cdot$ Fishing the line $\cdot$ Catch $\cdot$ Marine reserve $\cdot$ Marine protected area $\cdot$ MPA $\cdot$ Marine reserve border $\cdot$ Habitat $\cdot$ Collaborative $\cdot$ Panulirus interruptus

\section{INTRODUCTION}

Concern for populations targeted by marine fisheries has increased in recent decades and has motivated the establishment of no-take marine reserves in coastal oceans worldwide (UNEP-WCMC 2008). Marine reserves work by eliminating (or reducing) fishing mortality inside their borders, and numerous empirical studies have described reserve effects such as increased size, abundance and biomass of target organisms inside reserve borders (reviews by Côté et al. 2001, Halpern 2003, Lester et al. 2009). Reserve effects are often measured as average differences at sites inside versus outside single reserves, but dynamics of marine populations and the effects of marine reserves are probably subject to high spatial variability (MacCall 1990, García-Charton \& PérezRuzafa 1999, Prince 2005, Stelzenmüller et al. 2007). 
Identifying and controlling for drivers of spatial variability provides crucial information that improves predictions and assessments of reserve performance (Agardy et al. 2003, Sale et al. 2005). Two crucial drivers are habitat characteristics and the distance of sampling sites from reserve borders (Stelzenmüller et al. 2007, Harmelin-Vivien et al. 2008).

Theory suggests that reserve effects can vary as a function of distance from reserve borders because of the emigration of adult organisms from reserves (spillover). Spillover models predict gradients in relative abundance that peak near reserve centers, decline across borders into fished areas, and reach an asymptotic low value farther into fished areas (Kaunda-Arara \& Rose 2004, Hilborn et al. 2006). This theoretical pattern is driven by 2 assumptions: (1) target organisms immediately inside reserve borders are more likely to exit marine reserves and experience fishing mortality than conspecifics farther inside the reserve, and (2) the amount of time that an individual spends outside reserves, and the consequent vulnerability to fishing, increases with distance from reserve borders. Empirical studies designed to test for gradients in abundance or catch rates (a proxy for abundance) across or near reserve borders offer mixed support for model predictions (Chapman \& Kramer 1999, Kaunda-Arara \& Rose 2004, Abesamis et al. 2006, Goñi et al. 2006, 2008), and in many cases gradients are absent. The absence of gradients can be explained by factors other than lack of spillover, and these factors include concentrated fishing effort near borders (fishing the line) and high organism mobility (Goñi et al. 2006, Abesamis et al. 2006, Kellner et al. 2007). Another explanation is that heterogeneous habitat structure drives spatial patterns of abundance that alter or obscure spillover-driven gradients (Goñi et al. 2008, Harmelin-Vivien et al. 2008, Forcada et al. 2009).

Habitat structure can profoundly influence localscale demography (García-Charton \& Pérez-Ruzafa 1999) and is an essential consideration for assessments of area-based management strategies. Although relatively few marine reserve studies control for habitat structure heterogeneity, those that do so indicate that habitat can influence reserve effects. For example, the density and mean size of 7 and 13 fish species, respectively, were initially found to be greater inside a Barbados reserve than in nearby fished areas (Rakitin \& Kramer 1996). Subsequently, the same reserve was studied in a manner that controlled for the influence of habitat heterogeneity, and the same species sampled by Rakitin \& Kramer (1996) were not statistically larger or more abundant inside the reserve (Chapman \& Kramer 1999). Other studies indicate that fish assemblage characteristics (richness, diversity, abundance or biomass) are higher inside reserves but vary significantly across habitat types (Grigg 1994, Friedlander et al. 2007, Harmelin-Vivien et al. 2008). Recent work in the Mediterranean Sea indicates that habitat heterogeneity near reserve borders modifies how spillover affects catch rates (Stelzenmüller et al. 2007, Forcada et al. 2009). Reserve studies that consider the role of habitat typically focus on categorical definitions (e.g. seagrass meadows, rocky reef or sand), but smallscale structural features within a given habitat type can also influence organism abundance and/or reserve effects (Harmelin-Vivien et al. 2008). Despite this evidence, few studies measure specific habitat structural features within habitat types at sampling sites; consequently, there is a need for empirical studies that describe and control for fine-scale habitat features when exploring both the mean effects of reserves (i.e. differences at sites categorically inside versus outside) and the spatial extent of reserve effects.

Here we report the mean effects of reserves and the influence of distance from reserve borders on the number and size of California spiny lobster Panulirus interruptus trapped at sites across a reserve network at the Santa Barbara Channel Islands (SBCI), California, USA. Kay et al. $(2008,2012)$ report increased trap yield, mean size and a greater proportion of individuals in larger size classes inside versus outside reserves at SBCI sites. In the present study we explored mean effects of reserves on spiny lobster abundance and size, we describe how these effects change with distance from reserve borders, and we controlled for habitat variability across sites in 2 ways. First, we conducted visual habitat surveys at all sites to quantify fine-scale habitat features that may influence lobster abundance. Second, we compared trap yields for legal-sized lobsters with those for sublegal adults. Sublegal adult abundance is not directly reduced by fishing outside reserves, and sublegal abundance inside is assumed to be unlinked to adult abundance via reproduction because larvae of $P$. interruptus have a long planktonic period and probably disperse on scales much larger than the reefs and reserves in our study (Johnson 1960, Pringle 1986). Thus, our measurements of sublegal abundance provide a novel control for spatially variable factors (i.e. habitat) that could influence the distribution of harvestable adults and, therefore, bias perceived reserve effects. The result is a robust case study of $P$. interruptus responses to reserve protection that informs theoretical 
predictions regarding how reserves influence populations at varying spatial scales.

\section{MATERIALS AND METHODS}

\section{Site description and selection}

Our study was conducted at sites associated with 3 marine reserves at SBCI: Gull and Scorpion (Santa Cruz Island), and Carrington (Santa Rosa Island; Fig. 1). Use of the term 'network' in the marine reserve literature is often ambiguous and is seldom accompanied by a definition (but see Lubchenco et al. 2003, Christie \& White 2007). We refer to the SBCI reserves as a network because compared with an individual protected area (even a vast hypothetical reserve with the same total area as the SBCI reserves) they act as an integrated system that provides broader biogeographic coverage (Hamilton et al. 2010), replication for scientific study (Kay et al. 2012), increased spatial distribution and border extent for fisheries interaction via adult spillover and larval export (Gaines et al. 2010), greater buffer against catastrophe and protection of vulnerable species (Airamé et al. 2003), and because of their size and spacing characteristics, the individual reserves are likely to provide effective refugia for species with short larval dispersal but be linked for species with relatively longer larval dispersal (Shanks et al. 2003). SBCI reserves were established in 2003 and the reserves used in this study prohibit all commercial and recreational fishing within their borders. Additional characteristics of the SBCI marine reserve network (CDFG 2008), as well as the selection process for sites used in this study, are described elsewhere (Kay et al. 2012). Briefly, scientists and commercial
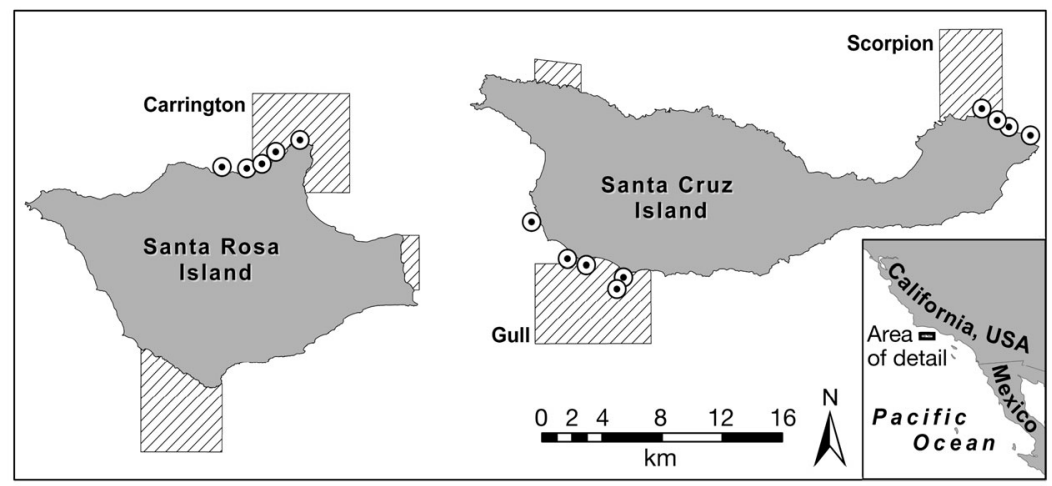

Fig. 1. Santa Cruz and Santa Rosa Islands in the Southern California Bight (inset), including the sites at Carrington, Gull and Scorpion reserves (marine reserves are hashed areas), where collaborative trapping and SCUBA habitat surveys took place $(\odot)$ lobster fishermen worked collaboratively to identify reefs located inside and outside reserves that had similar physical, ecological, oceanographic and fishery catch characteristics. Ultimately, we selected 4 trapping sites associated with the Scorpion reserve, and 5 at the larger Gull and Carrington reserves (14 total). Sites were spatially distributed near the center, immediately inside, adjacent outside and far outside of the reserve ( 2-6 $\mathrm{km}$ away) relative to a single border of each reserve (Fig. 1). We used GIS (ArcGIS 9.3.1, ESRI) to calculate the midpoint distance of each trapping site to the nearest reserve border.

\section{Collaborative trapping}

We deployed 10-15 replicate lobster traps at each of the sites associated with the 3 individual reserves (duplicated sites in the center of Gull and Carrington reserves received the same approximate effort as a single site; total traps $=10-15$ traps $\times 4$ trapping sites $=40-60$ traps per reserve). Traps were sampled every 1-4 d (with a small number of longer periods as a result of weather or vessel mechanical problems) over a 3 mo period at each site from August to October 2006, 2007 and 2008 (Appendix 1). Because the timing of sampling was not consistent across reserve sites, we controlled for the effects of variable soak time (number of days between sampling individual traps) and field season (2006, 2007 and 2008) in our analysis (see 'Statistical approach'). Traps used in this study were identical to those used in the fishery for Panulirus interruptus at SBCI and are described elsewhere (Kay et al. 2012).

In each trapping area, initial deployment of traps was conducted from a commercial lobster vessel or was guided by commercial lobstermen on the fishing grounds. Individual traps were placed haphazardly in stratified reef areas that were defined prior to fieldwork and which were delineated by bathymetry, sand-rocky reef interfaces and/or the extent of sea surface canopy formed by the giant kelp Macrocystis pyrifera. As each trap was retrieved, we recorded the depth, time, date and GPS coordinates, as well as the total number, sex and carapace length $\left(\mathrm{CL}_{i}\right.$ to the nearest $\mathrm{mm}$ using vernier calipers) of all lobsters in the trap. Additionally, movement and emigration rates of lobsters from sites inside reserves to fished areas outside 
reserves were studied with a tag-recapture study. Lobsters were tagged with an individually numbered T-bar tag (TBA-2 standard, Hallprint Tags) applied through a thin membrane on the ventral surface between the tail and carapace, such that the ' $\mathrm{T}$ ' portion of the tag was anchored in muscle and would persist through molting (some tag loss occurred but was not quantified and was assumed to be equal across sites). We minimized stress to lobsters on deck by shading them with wet burlap sacks, placing them in standing seawater and returning them to the ocean as quickly as possible. After lobsters had been processed, they were returned to the exact location of capture and released by hand at the sea surface.

\section{Habitat surveys}

We performed SCUBA surveys at each trapping site to identify and control for the potential influence of select habitat features on trap yield. During August-October 2008, we conducted 80 SCUBA transect surveys across 13 of the 14 trapping sites inside and outside of the reserves. At each site we conducted a minimum of 6 transect surveys, and transects were $45 \mathrm{~m}$ long $\times 10 \mathrm{~m}$ wide $\left(450 \mathrm{~m}^{2} \times\right.$ 6 transects per site $=\geq 2700 \mathrm{~m}^{2}$ of reef surveyed at each site shown in Fig. 1). Divers recorded the total number of dens and caves, and the extent of linear crack that could be occupied by lobsters on each transect. These 3 features were selected based upon prior analyses that identify them as critical habitat features for determining lobster abundance on reefs at our SBCI trapping sites (M. C. Kay unpubl. data).

Dens were defined as any cave-like voids in bedrock, boulders or biogenic structures (e.g. colonies of the sandcastle worm Phragmatopoma californica) that were enclosed on all sides except for 1-3 entrances (entrances no greater in diameter than the depth of the cave-like structure), and which 1-3 legal sized lobsters ( $\geq 82.5 \mathrm{~mm} \mathrm{CL}$ ) could occupy and use as defensible space in the presence of predators. Caves were defined as openings whose inner diameter exceeded the diameter of the entrance and that could serve as refuge for 4 or more legal-sized lobsters. Linear crack was defined as any fissure that was deep enough to be occupied by a legal-sized lobster but lacked the walls of a den or cave, such that a potential predator could approach a lobster from any direction in a $180^{\circ}$ arc (in 2-dimensional space) as opposed to the aperture of a den or cave entrance. A single diver (M. C. Kay) recorded these features on all transects to eliminate diver bias across sites.

\section{Statistical approach}

Our first objective was to compare trap performance (number of legal-sized lobsters [ $\geq 82.5 \mathrm{~mm}$ $\mathrm{CL}]$, the number of sublegal lobsters and the mean size of legal lobsters) inside versus outside the 3 reserves, and to simultaneously identify and control for the influence of the 3 fine-scale habitat features (dens, caves and crack). To accomplish this, we specified the following multiple regression model (Model 1):

$$
\begin{aligned}
Y= & \alpha+\gamma \text { Reserve }+\beta X+\varphi \text { Scorpion }+ \\
& \delta \text { Carrington }+\rho 2006+\omega 2007+\varepsilon
\end{aligned}
$$

where response variable $Y$ represents either the number of legal-sized ( $\geq 82.5 \mathrm{~mm})$ lobsters per trap, the number of sublegal lobsters per trap or the mean size of legal-sized lobsters in traps (i.e. the model was run separately for each of the 3 response variables); $\alpha$ is the intercept (constant) in each model; Reserve is a dummy variable for traps inside any reserve; $X$ is a column vector of the independent variables (trap depth, number of nights traps were deployed, number of dens, number of caves, and extent (m) of linear crack on reefs at each site); Scorpion and Carrington are categorical variables for sites associated with the Scorpion and Carrington reserves, with Gull the omitted category; 2006 and 2007 are categorical variables for data collected during those years, with 2008 the omitted category; and $\varepsilon$ is the error term (variance not explained by the model).

The coefficient $\gamma$ describes the influence of location relative to reserve (inside vs. outside any of the 3 reserves) on the response variables, and the coefficients in row vector $\beta$ describe the influence of each independent variable (column vector $X$ ) on the number of legal-sized lobsters, number of sublegal lobsters and mean size of legal lobsters caught. The coefficients $\varphi$ and $\delta$ account for the average differences in response variables by reserve using Gull as the basis for comparison, and $\rho$ and $\omega$ account for the average differences in response variables by year using 2008 as the basis for comparison.

Our second objective was to test the relationship between trap performance and distances of trapping sites from reserve borders, and to simultaneously identify and control for the influence of the 3 finescale habitat features (dens, caves and crack). The distance of each trapping area from the nearest reserve border was measured from the midpoint among traps at each area. These measurements replaced the Reserve dummy variable in Model 1, such that a new model (Model 2) was specified: 


$$
\begin{aligned}
Y= & \alpha+\text { Aindist }+ \text { youtdist }+\beta X+\varphi \text { Scorpion }+ \\
& \delta \text { Carrington }+\rho 2006+\omega 2007+\varepsilon
\end{aligned}
$$

where indist and outdist are distances of trapping areas inside and outside any reserve, respectively, and $\theta$ and $\gamma$ describe the influence of distance from reserve borders on trap performance in those areas. All other terms in Model 2 are as described above for Model 1, such that the influence of distance from reserve borders was measured while controlling for the influence of site specific habitat features.

Finally, we repeated our second objective (to test the relationship between trap performance and distances of trapping sites from reserve borders) through specification of the following model (Model 3), which allowed a nonlinear relationship between the response and predictor variables:

$$
\begin{aligned}
Y= & \alpha+\theta \text { indist }+\psi(\text { indist })^{2}+\text { youtdist }+ \\
& \xi(\text { outdist })^{2}+\beta X+\varphi \text { Scorpion }+ \\
& \delta \text { Carrington }+\rho 2006+\omega 2007+\varepsilon
\end{aligned}
$$

where (indist) ${ }^{2}$ and (outdist) $)^{2}$ are the only new terms introduced, and the coefficients $\psi$ and $\xi$ estimate the extent of any nonlinearity. All other terms are as described for Model 2.

After Models 1-3 were run as described above, they were repeated with one important alteration: the number of sublegal lobsters per trap was removed as a response variable and included in each model as a predictor variable. The models were the same in all other aspects. The 2 response variables for each model were: (1) the number of legal lobsters per trap and (2) the mean size of legal lobsters per trap. Running the 3 models sequentially (i.e. excluding and then including the number of sublegals per trap as a predictor variable) was fundamental to using sublegals per trap to control for habitat heterogeneity. Specifically, using the number of sublegals per trap as a response variable in Models 1-3 allowed us to determine whether trap yield for sublegals changed with regard to trap location inside, outside or with increasing distance form reserve borders (i.e. was influenced by the Reserve, indist and outdist predictor variables). We predicted that sublegals should not be influenced by reserve protection, as they are not removed by fishing, such that any influence of the Reserve, indist and outdist predictor variables is likely an artifact of habitat heterogeneity but not reserve effects per se. For models in which the number of sublegals per trap was a response variable, we determined a priori that significant coefficient values for the Reserve, indist and outdist predictors would be interpreted to indicate that habitat was variable among sites and responsible for any statistically significant trends in sublegal abundance. This is important because habitat heterogeneity that influences sublegal abundance is likely to also influence abundance and mean size of legal lobsters. Therefore, using the number of sublegals per trap as a predictor variable in the second set of models provides a control for habitat features that may drive perceived reserve effects reported for legal lobsters.

For all models, numerical values for habitat features (caves, dens and crack) that were measured during SCUBA surveys are the averages from 6 transects at each trapping area, such that all traps within an area were associated with a common score for each habitat variable. Similarly, the distance of each area from the nearest reserve border was measured as the average distance of all traps at an individual trapping area. Because of this averaging of trap distance and habitat scores, standard errors during the analyses were clustered for the 14 areas. This accounts for the fact that some covariates vary only at the level of the trapping area. In the statistical package we used to specify our models (STATA 9; StataCorp 2005), clustering standard errors invokes White's standard errors, which are robust to heteroscedasticity (Wooldridge 2009, Chap. 8). Statistical significance was determined at the 0.05 level. For each model we report the adjusted $\mathrm{R}^{2}$ value (appropriate when comparing models with different numbers of parameters; Zar 1999, p. 423) as well as Akaike's information criterion (AIC; estimated using the estat ic command in STATA).

\section{RESULTS}

\section{Model 1: Mean effects inside versus outside reserves}

After controlling for all variables in our model, traps that were deployed inside reserves captured an average of 5.49 more legal lobsters per trap than those placed outside reserves but only 0.92 more sublegal lobsters per trap, and for both response variables the differences were highly statistically significant (Table 1). These statistical results are also apparent in the raw data without controlling for any covariates (Fig. 2A,B). The number of legal lobsters caught was influenced by the mean density of both dens and caves at each trapping site (predictor variables Dens and Caves), such that each additional den or cave per $450 \mathrm{~m}^{2}$ had the marginal effect of increasing trap yield by 0.22 and 0.77 legal lobsters trap ${ }^{-1}$, 


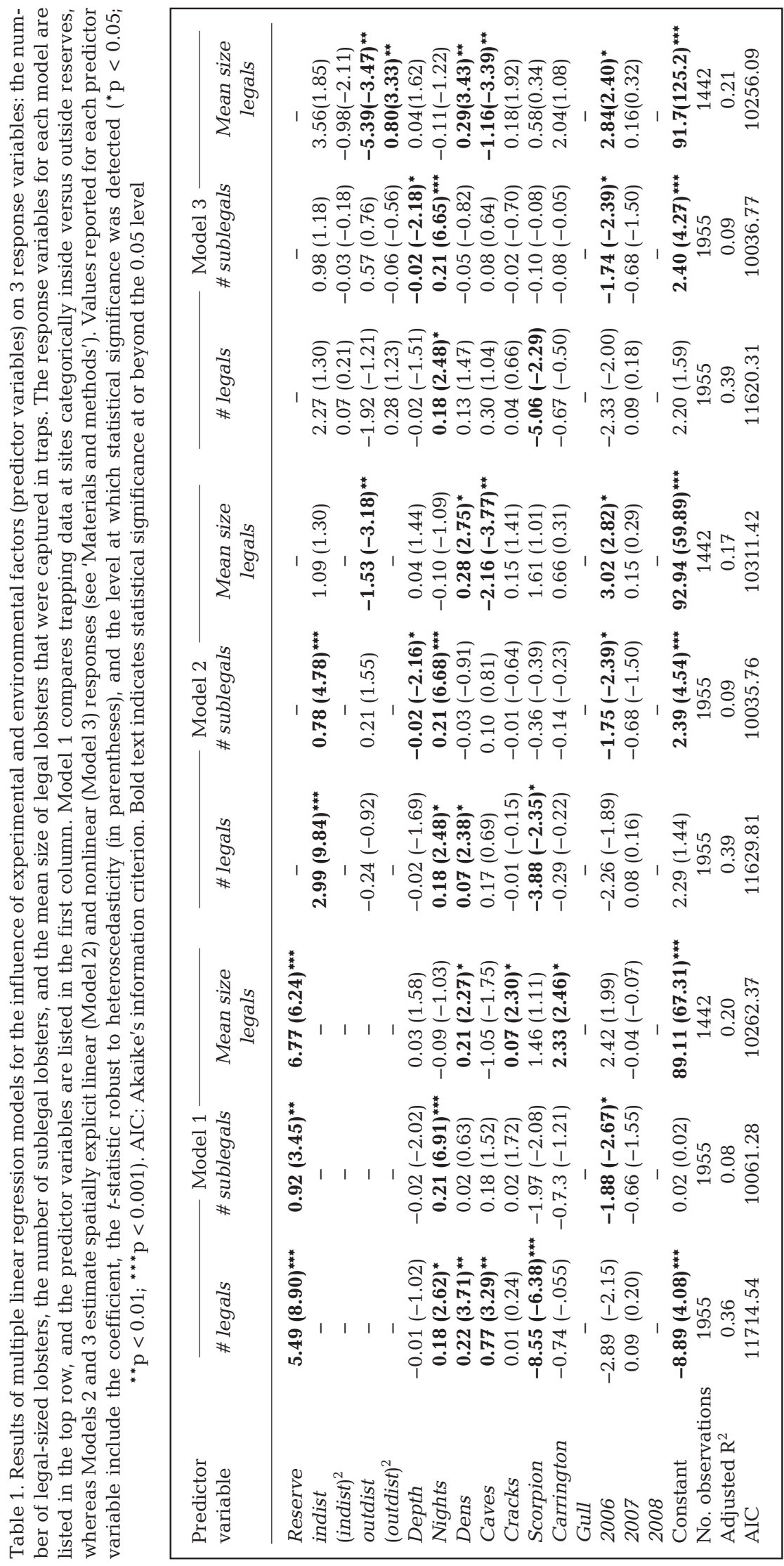

respectively (Table 1). In contrast, the extent of linear crack on transects did not influence trap yield.

Model 1 indicates that reserves increased the carapace length of legal lobsters inside versus outside reserves by an average $6.77 \mathrm{~mm}$, and the difference was highly significant (Table 1) and clearly represented in the raw data (Fig. 2C). The number of dens and extent of linear crack per $450 \mathrm{~m}^{2}$ influenced the mean size of legal lobsters trapped, such that each additional den and meter of crack resulted in a 0.21 and $0.07 \mathrm{~mm}$ increase in mean size, respectively. Mean size of legal lobsters trapped at Carrington was $2.33 \mathrm{~mm}$ larger than at Gull (the omitted category).

Specification of Model 1 to include the number of sublegals per trap as a predictor variable (Table 2) improved the explanatory power of the model (for response variable \# legals, the adjusted $\mathrm{R}^{2}$ increased from 0.36 to 0.51 and AIC decreased from 11714.54 to 11186.57 ; for response variable mean size legals, the adjusted $\mathrm{R}^{2}$ increased from 0.20 to 0.22 and AIC decreased from 10262.37 to 10231.11), and still indicates that reserves significantly influence the number and mean size of legal lobsters per trap despite the factors that caused sublegal trap yield to be higher inside than outside reserves. The coefficient describing the effect of the Reserve predictor on the \# legals response variable was slightly lower than in the original model (4.81 versus 5.49), and the difference $(0.68)$ is similar to the coefficient value $(\beta=0.74)$ for the \# sublegals predictor (Table 2), and indicates the extent to which the Reserve predictor in the original model was attributable to factors unrelated to reserve protection. The Dens, Caves and Crack predictors remained significant as in the original specification (but with slightly different coefficient values), and \# sublegals was a highly significant predictor for both response variables. 

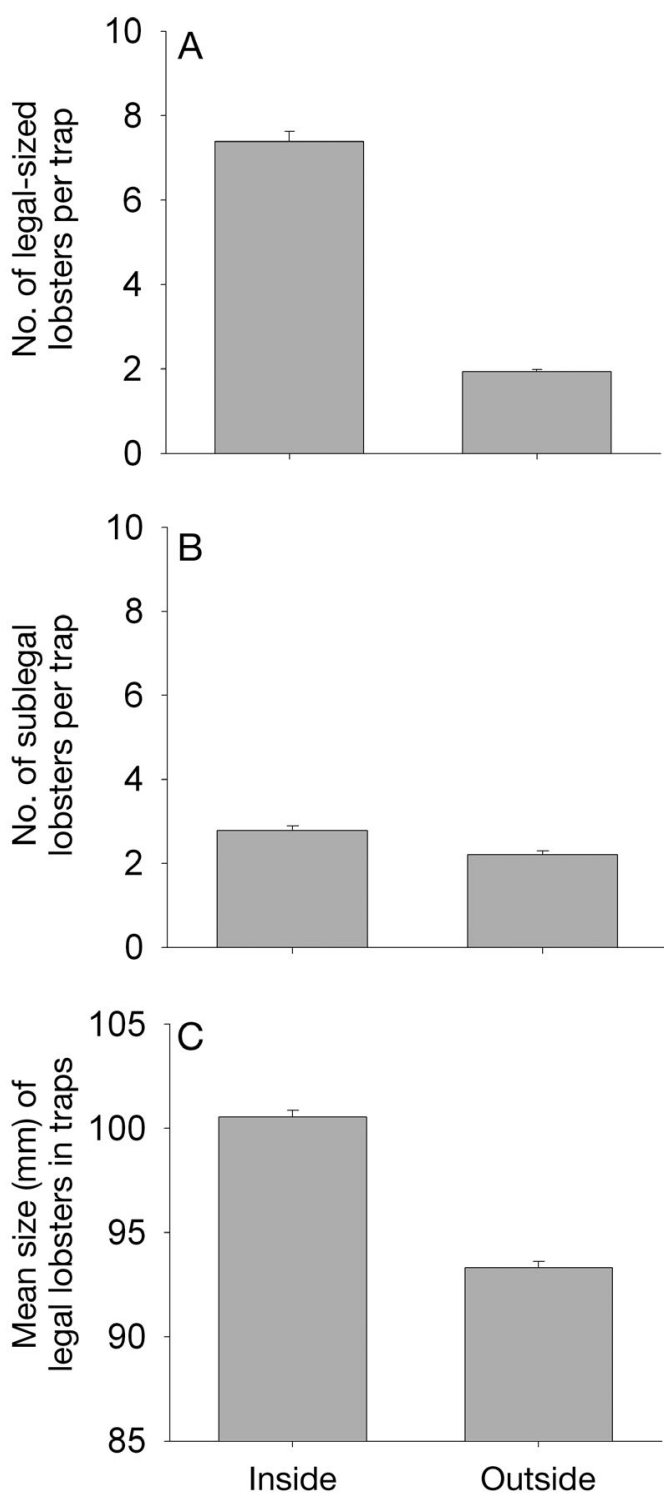

Fig. 2. Panulirus interruptus. Mean number of (A) legalsized ( $\geq 82.5 \mathrm{~mm}$ carapace length) and (B) sublegal lobsters, and $(C)$ the mean size (carapace length) of all legal-sized lobsters caught in traps inside versus outside the Carrington, Gull and Scorpion marine reserves $( \pm \mathrm{SE})$

To summarize, Model 1 controls for the statistically significant influences of fine-scale habitat features (e.g. dens), reserve site location (Gull, Scorpion or Carrington), and season (years 2006-2008), and indicates that all 3 response variables (\# legals, \# sublegals and mean size) were significantly influenced by location inside versus outside reserves. Including the number of sublegals as a predictor variable in Model 1, which serves as a proxy for unobserved aspects of habitat quality, improved the explanatory power of the model.

\section{Model 2: Influence of distance from borders (linear model)}

Among trapping sites inside of marine reserves, the distance of individual sites from the nearest reserve border (predictor variable indist) strongly influenced the number of legal lobsters per trap (Table 1), and the same trend is clearly present in the raw data (Fig. 3A). The statistically significant coefficient for indist $(\theta=2.99$ ) indicates that 2.99 more legal lobsters per trap were captured for every kilometer moved further inside reserves. Similarly, there was a significant relationship $(\theta=0.78)$ between distance inside borders and the number of sublegals per trap, but this statistical relationship is difficult to perceive in the raw data (Fig. 3B). For both legal and sublegal lobsters, there was no relationship between trap yield and distance outside of reserve borders, but the number of nights that traps were deployed (Nights predictor) significantly influenced yield of both size categories (Table 1).

The relationship between mean size of legal lobsters in traps and the distance of trapping sites outside of reserve borders (outdist) was statistically significant, although this trend is not apparent in the raw data (Fig. 3C). The negative coefficient value for outdist $(\gamma=-1.53)$ indicates that for each kilometer moved farther outside reserves, the mean size of legal lobsters declined by $1.53 \mathrm{~mm}$ (Table 1). In contrast, there was no relationship between legal lobster mean size and distance inside reserves. As with the \# legals and mean size response variables in Model 1, the number and mean size of legal lobsters in Model 2 were influenced by the number of dens observed on SCUBA transects. Specifically, for each additional den per $450 \mathrm{~m}^{2}$ transect, the number and mean size of legal lobsters in traps increased by 0.07 lobsters trap ${ }^{-1}$ and $0.28 \mathrm{~mm}$, respectively. Interestingly, each additional cave observed on transects resulted in a decreased mean size of $2.16 \mathrm{~mm}$ for legal lobsters in traps.

Specification of Model 2 to include \# sublegals as a predictor variable (Table 2) confirms the highly statistically significant relationship between distance inside reserves and the number of legal-sized lobsters per trap and improved the explanatory power of the model (adjusted $\mathrm{R}^{2}$ increased from 0.39 to 0.53 and AIC decreased from 11629.81 to 11118.71 ). The relationship between distance outside reserves and the mean size of lobsters in traps also remained significant, but the explanatory power of the model increased only slightly (adjusted $\mathrm{R}^{2}$ increased from 0.17 to 0.19 and AIC decreased from 10311.42 to 
Table 2. Results of multiple linear regression models (Models 1, 2 and 3) reported in Table 1, but for which the number of sublegal lobsters in each trap is used as a predictor variable. The rationale is that sublegals are ecologically similar to adults, but are not directly removed through fishing and therefore provide an additional control for the effect of habitat on the number and mean size of legal lobsters in traps. Values reported for each predictor variable include the coefficient, the $t$-statistic robust to heteroscedasticity (in parentheses), and the level at which statistical significance was detected $\left({ }^{*} \mathrm{p}<0.05\right.$; ${ }^{* *} \mathrm{p}<0.01$; ${ }^{* * *} \mathrm{p}<0.001$ ). Bold text indicates statistical significance at or beyond the 0.05 level

\begin{tabular}{|c|c|c|c|c|c|c|}
\hline \multirow{2}{*}{$\begin{array}{l}\text { Predictor } \\
\text { variable }\end{array}$} & \multicolumn{2}{|c|}{ Model 1} & \multicolumn{2}{|c|}{ Model 2} & \multicolumn{2}{|c|}{ Model 3} \\
\hline & \# legals & $\begin{array}{c}\text { Mean size } \\
\text { legals }\end{array}$ & \# legals & $\begin{array}{l}\text { Mean size } \\
\text { legals }\end{array}$ & \# legals & $\begin{array}{c}\text { Mean size } \\
\text { legals }\end{array}$ \\
\hline Reserve & $4.81(9.30)^{* * *}$ & $7.03(7.23)^{* * *}$ & - & - & - & - \\
\hline indist & - & - & $2.43(7.64)^{* * *}$ & $1.35(1.67)$ & $1.56(1.07)$ & $3.77(2.13)$ \\
\hline$(\text { indist })^{2}$ & - & - & - & - & $-0.10(0.31)$ & $-0.97(-2.22)^{*}$ \\
\hline outdist & - & - & $-0.40(-1.69)$ & $-1.41(-3.15)^{* *}$ & $-2.33(-1.87)$ & $-5.25(-3.43)^{* *}$ \\
\hline$(\text { outdist })^{2}$ & - & - & - & - & $0.33(1.82)$ & $0.80(3.33)^{* *}$ \\
\hline \# sublegals & $0.74(3.62)^{* *}$ & $-0.37(-3.67)^{* *}$ & $0.72(3.76)^{* *}$ & $-0.34(-3.66)^{* *}$ & $0.73(3.75)^{* *}$ & $-0.33(-3.48)^{* *}$ \\
\hline Depth & $0.003(0.62)$ & $0.03(1.51)$ & $-0.003(-0.67)$ & $0.03(1.36)$ & $-0.001(-0.20)$ & $0.03(1.53)$ \\
\hline Nights & $0.03(0.56)$ & $-0.01(-0.15)$ & $0.03(0.47)$ & $-0.03(-0.31)$ & $0.27(0.49)$ & $-0.04(-0.46)$ \\
\hline Dens & $0.20(4.56)^{* * *}$ & $0.21(2.78)^{*}$ & $0.10(3.36)^{* *}$ & $0.26(2.81)^{*}$ & $0.16(2.76)^{*}$ & $0.27(3.67)^{* *}$ \\
\hline Caves & $0.63(2.33)^{*}$ & $-0.97(-1.80)$ & $0.10(0.38)$ & $-2.10(-3.95)^{* *}$ & $0.24(0.99)$ & $-1.11(-3.37)^{* *}$ \\
\hline Cracks & $-0.01(-0.15)$ & $0.07(2.68)^{*}$ & $0.002(0.07)$ & $0.14(1.40)$ & $0.05(1.05)$ & $0.18(1.92)$ \\
\hline Scorpion & $-7.09(-6.57)^{* * *}$ & $0.78(0.75)$ & $-3.62(-2.31)^{*}$ & $1.56(1.05)$ & $-4.98(-2.91)^{*}$ & $0.54(0.33)$ \\
\hline Carrington & $-0.20(-0.18)$ & $2.01(2.54)^{*}$ & $-0.19(-0.18)$ & $0.59(0.29)$ & $-0.64(-0.58)$ & $1.96(1.08)$ \\
\hline Gull & - & - & - & - & - & - \\
\hline 2006 & $-1.49(-1.24)$ & $1.68(1.52)$ & $-0.99(-0.95)$ & $2.39(2.35)^{*}$ & $-1.06(-1.02)$ & $2.23(2.00)^{*}$ \\
\hline 2007 & $0.58(1.19)$ & $-0.30(-0.53)$ & $0.60(1.19)$ & $-0.10(-0.17)$ & $0.58(1.24)$ & $-0.09(-0.17)$ \\
\hline 2008 & - & - & - & - & - & - \\
\hline Constant & $-1.82(-1.66)$ & $90.09(73.19)^{* * *}$ & $0.57(0.47)$ & $93.97(58.53)^{* * *}$ & $0.46(0.44)$ & $92.81(122.05)^{* * *}$ \\
\hline No. observations & 1955 & 1442 & 1955 & 1442 & 1955 & 1442 \\
\hline Adjusted $\mathrm{R}^{2}$ & 0.51 & 0.22 & 0.53 & 0.19 & 0.53 & 0.22 \\
\hline $\mathrm{AIC}$ & 11186.57 & 10231.11 & 11118.71 & 10287.68 & 11099.24 & 10230.54 \\
\hline
\end{tabular}

10287.68). Both response variables in the model were significantly influenced by the number of dens observed on SCUBA transects, such that for each additional den per $450 \mathrm{~m}^{2}$ transect, the number and mean size of legal lobsters in traps increased by 0.10 lobsters trap ${ }^{-1}$ and $0.26 \mathrm{~mm}$, respectively.

\section{Model 3: Influence of distance from borders (nonlinear model)}

In the nonlinear model, neither the number of legal-sized lobsters nor the number of sublegal lobsters captured per trap was influenced by distance from borders inside or outside of reserves (Table 1). Similarly, the mean size of legal lobsters was not influenced by distance from reserve borders at sites inside reserves. Outside reserves, however, there was a relationship between distance from reserve borders and mean size of legal lobsters (Table 1), and coefficients for the predictors outdist and (outdist) ${ }^{2}$ were statistically significant. This result is consistent with distance-size relationship outside reserves reported for Model 2. Additionally, there was a sig- nificant relationship between mean size and the number of dens per $450 \mathrm{~m}^{2}$ transect, such that the addition of each den per $450 \mathrm{~m}^{2}$ resulted in an increased mean size of $0.29 \mathrm{~mm}$. As in Models 1 and 2, there was a negative relationship between cave abundance and mean size. Specification of Model 3 to include \# sublegals as a predictor variable (Table 2) increased the predictive power of the model, but interpretation of how reserves influence response variables in the original model is largely unchanged.

\section{DISCUSSION}

Our effort to minimize and statistically control for habitat heterogeneity across sites strengthens our conclusion that trap performance in this study was indeed influenced by the non-habitat predictor variables in our models, most notably the average effect of trap location inside versus outside reserves (Model 1; Fig. 2), and distance from reserve borders (Models 2 and 3; Fig. 3). Accounting for such factors represents a major challenge to marine ecologists (García-Charton \& 

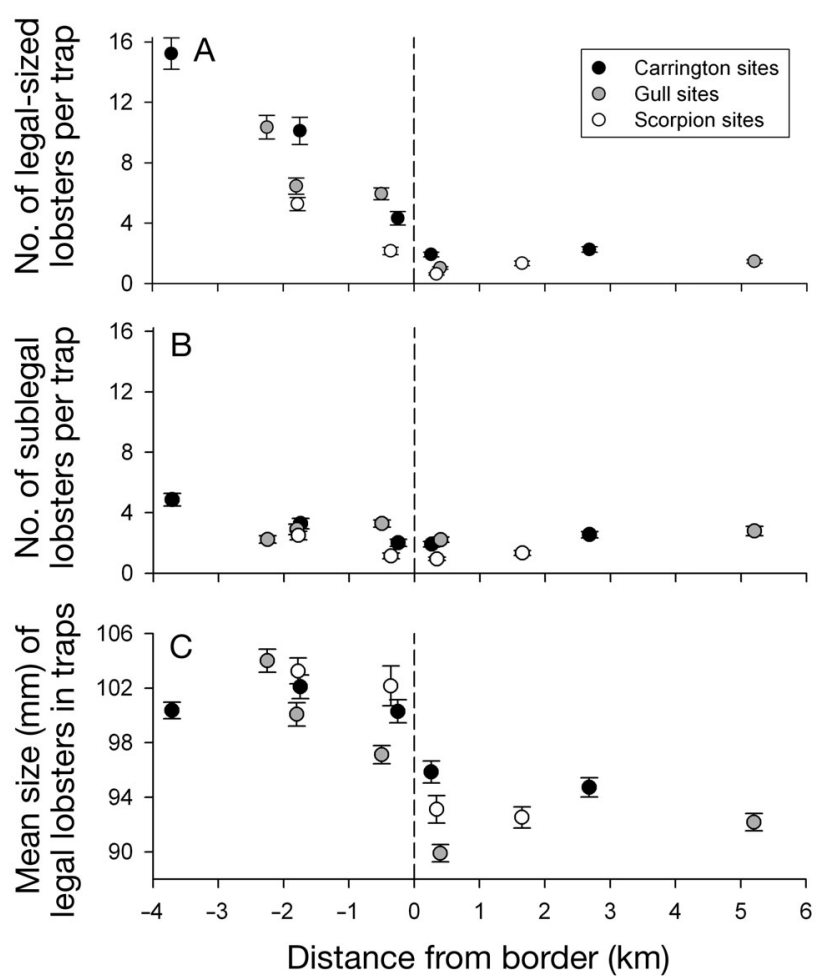

Fig. 3. Panulirus interruptus. Mean number of (A) legal-sized ( $\geq 82.5 \mathrm{~mm}$ carapace length) and (B) sublegal lobsters, and (C) the mean size (carapace length) of all legal sized lobsters trapped at sites associated with the Carrington, Gull and Scorpion marine reserves $( \pm \mathrm{SE})$ versus the distance of each site from the nearest reserve border (vertical dashed lines)

Pérez-Ruzafa 1999, Sale et al. 2005) and affects stakeholder confidence in reserve science (Agardy et al. 2003). An important step in minimizing habitat bias was the inclusion of commercial fishermen, whose local ecological knowledge (Hartley \& Robertson 2008) was essential for identifying reefs with similar physical characteristics and historical fishing production (Kay et al. 2012). Evidence that we were successful in selecting such reefs is suggested by catch patterns among sublegal lobsters, for which variation among sites was relatively low (Fig. 3B).

Although differences in sublegal catch across sites was lower than legal catch, sublegal trap yield was higher inside reserves and increased with distance inside reserve borders. These results are most likely driven by site-specific habitat differences because sublegal lobsters are not taken in the commercial or recreational fisheries for Panulirus interruptus. (Increased habitat quality at reserve interior sites is also suggested by patterns of den abundance; Fig. 4A). Thus, inclusion of \# sublegals as a predictor variable (Table 2) provided a valuable additional control for habitat heterogeneity across sites. This is reflected by the increased explanatory power (i.e. higher adjusted $\mathrm{R}^{2}$ and lower AIC) of models that include the \# sublegals predictor. The reliability of sublegal adult lobster abundance as a proxy for habitat used by legal-sized adults hinges upon 2 assumptions. The first is that legals and sublegals occupy and utilize similar habitat types. This assumption is valid since we consistently observed both size classes intermingled in our traps and on the seafloor. Second, use of sublegals as a predictor would violate a fundamental assumption of regression analysis if the response variable (legal-sized adults) influenced the predictor (sublegal abundance) through mechanisms such as avoidance and/or attraction. Avoidance is unlikely because we consistently observed that both size classes intermingled. Attraction is more likely than avoidance as spiny lobsters display various degrees of social interaction and gregariousness (reviewed by Childress 2007). Such interaction is unlikely to have driven the sublegal distributions we observed, however, because the differential distribution of sublegal
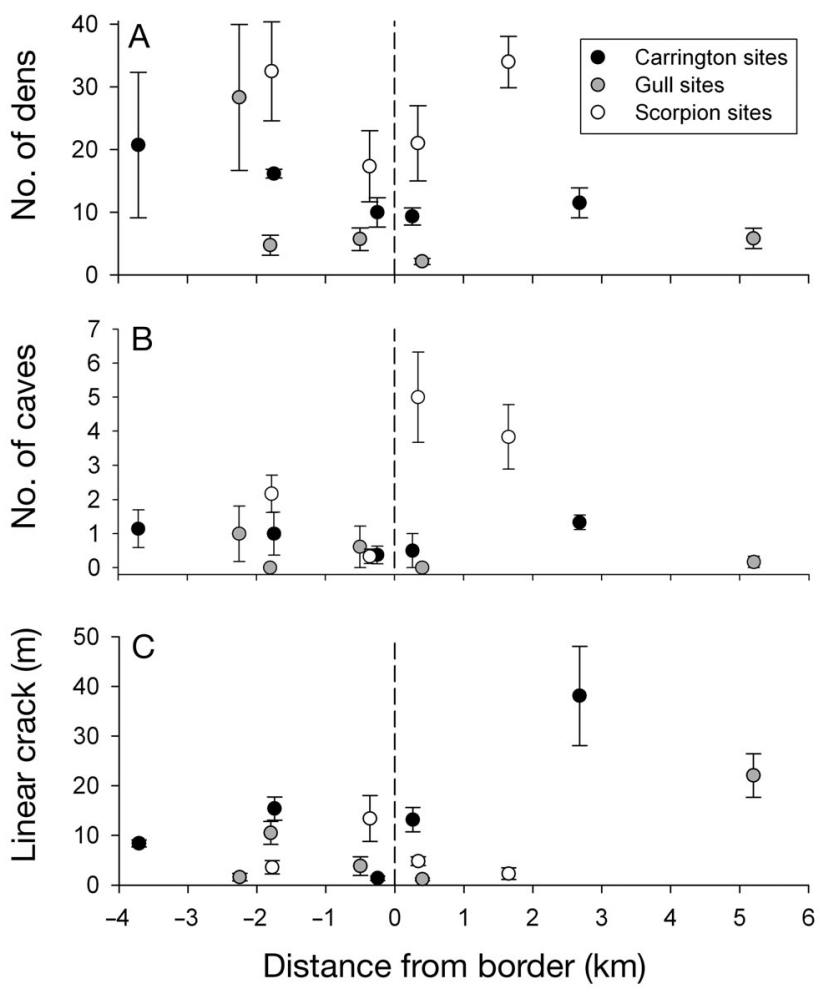

Fig. 4. Number of (A) dens and (B) caves, and (C) the linear extent $(\mathrm{m})$ of crack recorded on rocky reef trapping sites $( \pm \mathrm{SE})$ versus the distance of each site from the nearest reserve border (vertical dashed lines). Data were collected with SCUBA; means are from $6-8$ replicate $450 \mathrm{~m}^{2}$ transects at each site 
and legal-sized lobsters near reserve borders (i.e. Fig. 3A vs. Fig. 3B) existed at spatial scales encompassed by adult $P$. interruptus movement (Kay et al. 2008), thereby suggesting that sublegal adults were primarily distributed according to factors other than attraction to legal-sized adults.

Comparison of models with and without the \# sublegals predictor (i.e. Table 1 vs. Table 2) suggests that perceived reserve effects for models without this predictor were partially driven by factors unrelated to reserve protection. For example, in the specification of Model 1 in which \# sublegals was used as a predictor, the influence of the reserves on the \# legals response variable was lower than in the original model (4.81 vs. 5.49). The difference (0.68) is similar to the coefficient value for the \# sublegals predictor $(0.74)$, and indicates that $0.68-0.74$ of the 5.49 more lobsters per trap indicated by the Reserve coefficient in the original model (Table 1) was due to factors unrelated to reserve protection. Similarly, the indist coefficient was higher $(\theta=2.99)$ in the original Model 2 than in the specification with sublegals as a predictor $(\theta=2.43)$, and in the latter model the \# sublegals predictor was highly significant. These facts indicate that the perceived effect of distance from reserve borders reported in Table 1 was partially driven by factors that also influence the trap yield of sublegal lobsters (i.e. factors unrelated to reserve protection).

Our conclusion that variable sublegal trap yield is in fact caused by site-specific habitat differences, which in turn account for the observed influence of Reserve and indist predictors on sublegal catch, is vulnerable to 2 alternative explanations. The first is that fishing does indeed cause mortality among sublegals through interactions with fishing gear, predators or handling stress (e.g. Gooding 1985, DiNardo et al. 2002). This seems unlikely because traps used in the commercial fishery are equipped (by law) with escape ports for sublegal lobsters, but escape ports were absent on the traps we used in our sampling. Consequently, traps used in this study captured lobster size classes that are not (or minimally) captured by standard commercial traps (M. C. Kay unpubl. data). The second alternative is that increased biomass of adults inside reserves leads to increased reproduction and sublegal abundance. Although this is probably true for some species, it cannot be the case in our study because the reserves were younger than the time required for lobsters to increase in abundance inside reserves and produce offspring that grew to sublegal sizes that we trapped (M. C. Kay unpubl. data), and because larvae of Panulirus inter- ruptus have a planktonic period of 8-10 mo and are probably advected far from parental sites by ocean currents (Johnson 1960, Pringle 1986).

The importance of sampling for fine-scale habitat features is suggested by variation in these features among sites (Fig. 4) and the fact that dens (and to a lesser extent, caves and linear crack) significantly influenced response variables in most models (Tables 1, 2). At all 3 reserves (Gull, Scorpion and Carrington), sites closest to the center generally had higher den density than sites immediately inside borders (Fig. 4A). This condition was predicted by our collaborative fishery partners, who correctly anticipated that such fine-scale habitat differences would influence trapping rates. Among reserve studies that measure or control for habitat effects, habitat is often defined in broad categories (e.g. rocky reef, sand and seagrass meadows) with some measure of topographic relief (Grigg 1994, Stelzenmüller et al. 2007, Forcada et al. 2009). Our results support previous observations that fine-scale structural features within such broader habitats (here, the number of dens within rocky reef) can modify catch or abundance (Chapman \& Kramer 1999, Harmelin-Vivien et al. 2008). This may be especially true for spiny lobster species that show strong affinities for specific habitat features (Eggleston \& Dahlgren 2001, Mai \& Hovel 2007). Although measurements of fine-scale habitat features are often prohibitively expensive or logistically difficult, considering this level of detail in spatial planning and assessment may improve and inform area-based management schemes. High-resolution acoustic mapping of seafloors is increasing rapidly around the world, and can greatly facilitate approaches like the one described here for assessing the relative effects of habitat variation and marine reserves. Such maps do not exist for the area we studied, but the combination of SCUBA habitat surveys and patterns of sublegal abundance provide a level of habitat control that is absent from studies that estimate effects of reserves (and, antithetically, fishing) on target species.

Several interesting relationships between catch and the distance of trapping sites from reserve borders emerge from our analyses. First, the decline in the number of lobsters trapped as one moves from the center of reserves towards borders (at sites inside reserves), and from borders further into fished areas, is indicative of net emigration of adults from reserves (spillover) as described by theory (Hilborn et al. 2006, Moffitt et al. 2009) and empirical data (McClanahan \& Mangi 2000, Kaunda-Arara \& Rose 2004, Goñi et al. 2006). This result suggests that some degree of 
spillover is occurring at the SBCI reserves. Kay et al. (2012) did not detect spillover with a study design that compared trap yield and recapture of tagged lobsters at multiple sites outside reserves and mean values from sites inside reserve borders. This suggests that detection of gradients via spatially explicit sampling inside reserves might be a more sensitive measure of spillover from reserves, because emigration is not always detectable in fisheries catches outside reserves. Indeed, spillover of lobsters at SBCI appears to have much less of an impact on fishery catch and effort than in other lobster fisheries (e.g. Goñi et al. 2006, 2010), as suggested by the nonsignificant coefficient value relating catch outside and distance from borders (Table 1, Model 2, outdist), and the fact that, as of 2008, lobster fishermen at SBCI do not concentrate effort at reserve borders (Kay et al. 2012).

Another important finding from our study is that the relationship between distance of trapping sites from reserve borders (hereafter, border distance) and the number of lobsters caught per trap is relatively steep (and statistically significant) for sites inside reserves, but much less steep and not significant outside reserves (Fig. 3A, Table 1, Model 2). This difference is noteworthy because spillover-mediated changes in catch and/or abundance across reserve borders are commonly described with single functions (linear and nonlinear) fitted to data from all sites inside and outside a given reserve (Chapman \& Kramer 1999, Kaunda-Arara \& Rose 2004, Abesamis et al. 2006, Halpern et al. 2010). The pattern we observed indicates that spillover-mediated catch gradients may not be accurately described by a single function; this pattern is more similar to piecewise theoretical predictions of Kellner et al. (2007). Interestingly, Kellner et al. (2007) predicted that such differences can be caused by fishing the line, a behavior that was absent at our study sites (Kay et al. 2012). A potential explanation is that over time, spillover alone resulted in a relatively steep abundance gradient inside reserves, but moderate annual harvest rates at SBCI (Kay et al. 2012) precluded the buildup of lobsters immediately outside reserves.

The catch-border distance patterns we observed provide valuable information about reserves as tools for conservation and fisheries management. From a conservation standpoint, catch-border distance patterns indicate that refuge from fishing mortality is not spatially uniform inside reserves. Rather, fisherymarine reserve interactions (i.e. spillover) at SBCI likely cause low-level fishing mortality inside reserves that is highest near borders and declines towards reserve centers. Preliminary results of a collaborative tag-recapture program at our study reserves support this conclusion. Specifically, lobsters tagged by scientists inside reserves and later recaptured by commercial fishermen during fishing operations showed an inverse relationship between the distance of sites inside reserve borders and the proportion of animals that were later captured in the fishery outside reserves (Fig. 5). This spatially differential catch pattern supports the theoretical predictions of spillover (Hilborn et al. 2006). Despite apparent spillover, the average effect of reserve protection was robust and resulted in increased numbers and mean size of lobsters per trap (Fig. 2A,C, Table 1), even for populations near reserve borders (Fig. 3A,C). The extent to which spillover compensates for lost revenue due to SBCI reserves is unknown and likely to be negligible at present (Guenther 2010) but will probably increase in the future and is an area of need for continued research (Kay et al. 2012).

Catch-border distance patterns impact 2 specific applications of reserves as fishery management tools. First, reserves are emerging as tools for referencebased stock assessments that use protected populations as proxies for unfished conditions (Morgan et al. 2000, Willis \& Millar 2005, Babcock \& MacCall 2010, Wilson et al. 2010). Second, the biomass that is protected inside reserves is widely cited as a tool that buffers against stock decline or environmental stochasticity, but fishery scientists are only recently addressing the challenge of incorporating the protected biomass into stock assessments (Field et al. 2006). To limit bias in these 2 applications of marine reserves for stock assessment, it is imperative to measure representative population structures (for refer-

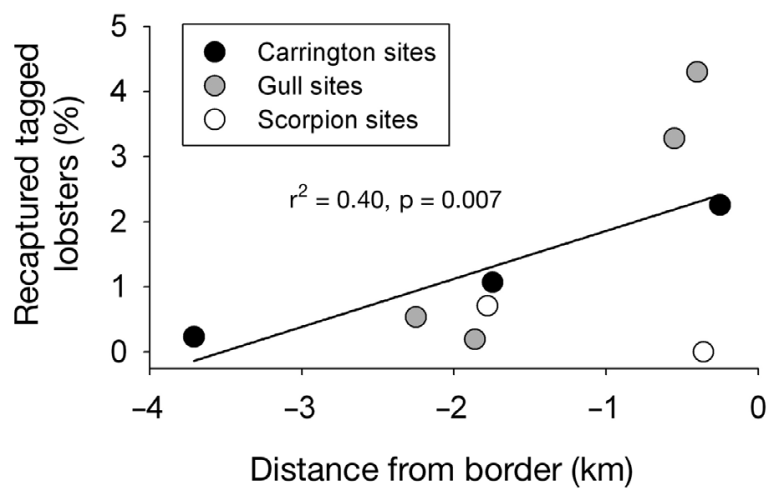

Fig. 5. Panulirus interruptus. Percentage of tagged lobsters, at each site inside reserves, that were later recaptured and reported by fishermen outside reserves versus the distance of each site from the nearest reserve border 
ence-based assessments) and the true proportion of a stock that is protected inside reserves (for assessments that include the protected portion of a stock). Finally, spatial patterns in size and abundance likely influence reproductive output of reserve populations, thereby impacting the extent of larval export to adjacent fisheries (Botsford et al. 2009). Here, we provide a quantitative estimate of how organism size and abundance is likely to change relative to location inside marine reserves.

The success of new resource management schemes must be addressed with appropriate science and monitoring, and simply changing management tactics without adequate capacity for assessment is unlikely to be a formula for success (Murray et al. 1999, Carr \& Raimondi 1999). With regard to area-based management strategies, fundamental considerations include spatially explicit responses of populations and fisheries. This study features an analytical approach for considering and controlling for 2 important spatial variables (habitat structure and distance from reserve borders) that can inform the implementation and assessment of reserves. Our spatially explicit integration of visual surveys and fishery relevant metrics, as well as the use of sublegal animals to control for habitat effects, are unique in the marine reserve literature. Detailed spatial measurements not only enhance assessments, but may help optimize the design of management strategies as human pressures on marine resources continue to increase globally.

Acknowledgements. This study was made possible by the involvement of many fishermen that did not participate as authors, in particular: S. Davis, R. Kennedy, M. Becker, K. Bortolazzo, J. Peters, R. Ellis, M. Brubaker and broker/ ombudsman T. Wahab. The authors thank R. Parrish (NOAA Fisheries) for his guidance. Tireless field assistance was provided by S. Rathbone, J. Heard and S. Horwath. Funding for this work was provided by California Ocean Protection Council/California Coastal Conservancy research award 07021 to M.C.K., H.S.L. and J. Wilson, a grant from the University of California Office of the President-Coastal Environmental Quality Initiative Award SB 060020 to H.S.L., C. Costello and P. Dayton, and student support from the National Science Foundation's Santa Barbara Coastal LongTerm Ecological Research (SBC-LTER) Program. The manuscript was improved by comments from B. Miller and 3 anonymous reviewers.

\section{LITERATURE CITED}

Abesamis RA, Russ GR, Alcala AC (2006) Gradients of abundance of fish across no-take marine reserve boundaries: evidence from Philippine coral reefs. Aquat Conserv Mar Freshw Ecosyst 16:349-371

Agardy TS, Bridgewater P, Crosby MP, Day J and others (2003) Dangerous targets? Unresolved issues and ideo- logical clashes around marine protected areas. Aquat Conserv Mar Freshw Ecosyst 13:353-367

Airamé S, Dugan JE, Lafferty KD, Leslie H, McArdle DA, Warner RR (2003) Applying ecological criteria to marine reserve design: a case study from the California Channel Islands. Ecol Appl 13(Suppl.):170-184

Babcock EA, MacCall AD (2010) How useful is the ratio of fish density outside versus inside no-take marine reserves as a metric for fishery management control rules? Can J Fish Aquat Sci 68:343-359

Botsford LW, Brumbaugh DR, Grimes C, Kellner JB and others (2009) Connectivity, sustainability, and yield: bridging the gap between conventional fisheries management and marine protected areas. Rev Fish Biol Fish 19:69-95

Carr MH, Raimondi PT (1999) Marine protected areas as a precautionary approach to management. Cal Coop Ocean Fish Invest Rep 40:71-76

CDFG (California Department of Fish and Game) (2008) Channel Islands marine protected areas: first 5 years of monitoring: 2003-2008. California Department of Fish and Game, Monterey, CA. Available at www.dfg.ca.gov/ marine

Chapman MR, Kramer DL (1999) Gradients in coral reef fish density and size across the Barbados Marine Reserve boundary: effects of reserve protection and habitat characteristics. Mar Ecol Prog Ser 181:81-96

Childress MJ (2007) Comparative sociobiology of spiny lobsters. In: Baeza JA, Thiel M (eds) Evolutionary ecology of social and sexual systems: crustaceans as model organisms. Oxford University Press, New York, NY, p 271-293

Christie P, White AT (2007) Best practices for improved governance of coral reef marine protected areas. Coral Reefs 26:1047-1056

Côté IM, Mosqueira I, Reynolds JD (2001) Effects of marine reserve characteristics on the protection of fish populations: a meta analysis. J Fish Biol 59 (Suppl A):178-189

DiNardo GT, DeMartini EE, Haight WR (2002) Estimates of lobster-handling mortality associated with the Northwestern Hawaiian Islands lobster-trap fishery. Fish Bull 100:128-134

> Eggleston DB, Dahlgren CP (2001) Distribution and abundance of Caribbean spiny lobsters in the Key West National Wildlife Refuge: relationship to habitat features and impact of an intensive recreational fishery. Mar Freshw Res 52:1567-1576

Field JC, Punt AE, Methot RD, Thomson CJ (2006) Does MPA mean 'major problem for assessments'? Considering the consequences of place-based management systems. Fish Fish 7:284-302

Forcada A, Valle C, Bonhomme P, Criquet G, Cadiou G, Lenfant P, Sánchez-Lizaso JL (2009) Effects of habitat on spillover from marine protected areas to artisanal fisheries. Mar Ecol Prog Ser 379:197-211

> Friedlander AM, Brown EK, Monaco ME (2007) Coupling ecology and GIS to evaluate efficacy of marine protected areas in Hawaii. Ecol Appl 17:715-730

Gaines SD, White C, Carr MH, Palumbi SR (2010) Designing marine reserve networks for both conservation and fisheries management. Proc Natl Acad Sci USA 107: 18286-18293

> García-Charton JA, Pérez-Ruzafa A (1999) Ecological heterogeneity and the evaluation of the effects of marine reserves. Fish Res 42:1-20 
Goñi R, Quetglas A, Reñones O (2006) Spillover of spiny lobsters Palinuris elephas from a marine reserve to an adjoining fishery. Mar Ecol Prog Ser 308:207-219

Goñi R, Adlerstein S, Alvarez-Berastegui D, Forcada A and others (2008) Spillover from six western Mediterranean marine protected areas: evidence from artisanal fisheries. Mar Ecol Prog Ser 366:159-174

> Goñi R, Hilborn R, Díaz D, Mallol S, Alderstein S (2010) Net contribution of spillover from a marine reserve to fishery catches. Mar Ecol Prog Ser 400:233-243

Gooding RM (1985) Predation on released spiny lobster, Panulirus marginatus, during tests in the northwestern Hawaiian Islands. Mar Fish Rev 47:27-35

Grigg RW (1994) Effects of sewage discharge, fishing pressure and habitat complexity on coral ecosystems and reef fishes in Hawaii. Mar Ecol Prog Ser 103:25-34

Guenther CM (2010) A socio-ecological analysis of marine protected areas and commercial lobster fishing in the Santa Barbara Channel, California. PhD dissertation, University of California, Santa Barbara, CA

> Halpern BS (2003) The impact of marine reserves: do reserves work and does reserve size matter? Ecol Appl 13(Suppl):117-137

Halpern BS, Lester SE, Kellner JB (2010) Spillover from marine reserves and the replenishment of fished stocks. Environ Conserv 36:268-276

> Hamilton SL, Caselle JE, Malone DP, Carr MH (2010) Incorporating biogeography into evaluations of the Channel Islands marine reserve network. Proc Natl Acad Sci USA 107:18272-18277

Harmelin-Vivien M, Le Diréach L, Bayle-Sempere J, Charbonnel E and others (2008) Gradients of abundance and biomass across reserve boundaries in six Mediterranean marine protected areas: Evidence of fish spillover? Biol Conserv 141:1829-1839

> Hartley TW, Robertson RA (2008) Stakeholder collaboration in fisheries research: integrating knowledge among fishing leaders and science partners in northern New England. Soc Nat Resour 22:42-55

> Hilborn R, Micheli F, De Leo GA (2006) Integrating marine protected areas with catch regulation. Can J Fish Aquat Sci 63:642-649

Johnson MW (1960) The offshore drift of larvae of the California spiny lobster, Panulirus interruptus. Cal Coop Ocean Fish Invest 7:147-161

Kaunda-Arara B, Rose GA (2004) Effects of marine reef National Parks on fishery CPUE in Coastal Kenya. Biol Conserv 118:1-13

Kay MC, Lenihan HS, Miller CJ, Barsky K (2008) Numbers, body size, and movement of lobster. In: Airame $\mathrm{S}$, Ugoretz J (eds) Channel Islands marine protected areas: first 5 years of monitoring. California Department of Fish and Game, Santa Barbara, CA, p 8-9

Kay MC, Lenihan HS, Guenther CM, Wilson JR, Miller CJ, Shrout SW (2012) Collaborative assessment of spiny lobster (Panulirus interruptus) population and fisheries responses to a marine reserve network. Ecol Appl 22: 322-335

Kellner JB, Tetreault I, Gaines SD, Nisbet RM (2007) Fishing the line near marine reserves in single and multispecies fisheries. Ecol Appl 17:1039-1054
Lester SE, Halpern BS, Grorud-Colvert K, Lubchenco J and others (2009) Biological effects within no-take marine reserves: a global synthesis. Mar Ecol Prog Ser 384: 33-46

> Lubchenco J, Palumbi SR, Gaines SD, Andelman S (2003) Plugging a hole in the ocean: the emerging science of marine reserves. Ecol Appl 13(Suppl):3-7

MacCall AD (1990) Dynamic geography of marine fish populations. Washington Sea Grant, Seattle, WA

> Mai TT, Hovel KA (2007) Influence of local-scale and landscape-scale habitat characteristics on California spiny lobster (Panulirus interruptus) abundance and survival. Mar Freshw Res 58:419-428

McClanahan TR, Mangi S (2000) Spillover of exploitable fishes from a marine park and its effects on the adjacent fishery. Ecol Appl 10:1792-1805

Moffitt EA, Botsford LW, Kaplan DM, O'Farrell MR (2009) Marine reserve networks for species that move within a home range. Ecol Appl 19:1835-1847

> Morgan LE, Botsford LW, Wing SR, Smith BD (2000) Spatial variability in growth and mortality of the red sea urchin, Strongylocentrotus franciscanus, in northern California. Can J Fish Aquat Sci 57:980-992

Murray SN, Ambrose RF, Bohnsack JA, Botsford LW and others (1999) No-take reserve networks: sustaining fishery populations and marine ecosystems. Fisheries 24: $11-25$

Prince JD (2005) Combating the tyranny of scale for haliotids: micro-management for microstocks. Bull Mar Sci 76:557-578

Pringle JD (1986) California spiny lobster (Panulirus interruptus) larval retention and recruitment: a review and synthesis. Can J Fish Aquat Sci 43:2142-2152

Rakitin A, Kramer DL (1996) Effect of a marine reserve on the distribution of coral reef fishes in Barbados. Mar Ecol Prog Ser 131:97-113

Sale PF, Cowen RK, Danilowicz BS, Jones GP and others (2005) Critical science gaps impede use of no-take fishery reserves. Trends Ecol Evol 20:74-80

Shanks AL, Grantham BA, Carr MH (2003) Propagule dispersal distance and the size and spacing of marine reserves. Ecol Appl 13(Suppl):159-169

StatCorp (2005) STATA 5: data analysis and statistical software. Stata Corporation, College Station, TX

> Stelzenmüller V, Maynou F, Martin P (2007) Spatial assessment of benefits of a coastal Mediterranean marine protected area. Biol Conserv 136:571-583

UNEP-WCMC (2008) National and regional networks of marine protected areas: a review of progress. United Nations Environment Programme World Conservation Monitoring Centre, Cambridge

Willis TJ, Millar RB (2005) Using marine reserves to estimate fishing mortality. Ecol Lett 8:47-52

Wilson JR, Prince JD, Lenihan HS (2010) A management strategy for sedentary nearshore species that uses marine protected areas as a reference. Mar Coast Fish: Dyn Manag Ecosyst Sci 2:14-27

Wooldridge JM (2009) Introductory econometrics. SouthWestern CENGAGE Learning, Mason, OH

Zar JH (1999) Biostatistical analysis. Prentice Hall, Upper Saddle River, NJ 
Appendix 1. Summary of sampling dates at each marine reserve

\begin{tabular}{|llr|}
\hline \multicolumn{1}{|l}{ Gull } & Scorpion & Carrington \\
\hline 13 Sep 2006 & 10 Sep 2007 & 7 Sep 2007 \\
16 Sep 2006 & 13 Sep 2007 & 10 Sep 2007 \\
21 Sep 2006 & 14 Sep 2007 & 17 Sep 2007 \\
28 Sep 2006 & 18 Sep 2007 & 20 Sep 2007 \\
6 Oct 2006 & 21 Sep 2007 & 25 Sep 2007 \\
19 Oct 2006 & 23 Sep 2007 & 28 Sep 2007 \\
7 Aug 2007 & 28 Sep 2007 & 3 Oct 2007 \\
10 Aug 2007 & 1 Oct 2007 & 6 Aug 2008 \\
17 Aug 2007 & 7 Oct 2007 & 11 Aug 2008 \\
21 Aug 2007 & 10 Oct 2007 & 14 Aug 2008 \\
25 Aug 2007 & 14 Oct 2007 & 18 Aug 2008 \\
31 Aug 2007 & 19 Oct 2007 & 22 Aug 2008 \\
6 Sep 2007 & 25 Oct 2007 & 25 Aug 2008 \\
3 Sep 2008 & 29 Oct 2007 & 28 Aug 2008 \\
5 Sep 2008 & 2 Nov 2007 & 30 Sep 2008 \\
8 Sep 2008 & & \\
12 Sep 2008 & & \\
16 Sep 2008 & & \\
23 Sep 2008 & & \\
\hline
\end{tabular}

Editorial responsibility: Omar Defeo, Montevideo, Uruguay
Submitted: August 5, 2011; Accepted: January 11, 2012 Proofs received from author(s): March 23, 2012 